\title{
Technical note: Method for improving precision of in-parlor milk meters and adjusting milk weights for stall effects
}

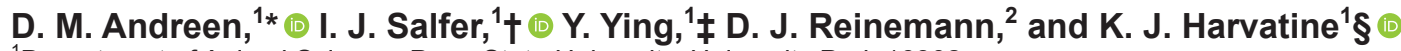 \\ ${ }^{1}$ Department of Animal Science, Penn State University, University Park 16802 \\ ${ }^{2}$ Department of Biological Systems Engineering, University of Wisconsin, Madison 53706
}

\begin{abstract}
Milk yield is a fundamental observation in most dairy experiments and is commonly determined using integrated milk meters that measure milk weight as the cow is being milked. These meters are heavily used in a harsh environment and often are not regularly calibrated, so calibration errors and mechanical problems may create artificial variation in milk weight data. Additionally, direct calibration by collection of milk in a bucket is difficult and imperfect because the use of the bucket may affect yield recorded by the milk meter. The objective of this work was to define a method to easily check parlor meter precision and adjust milk weight values for variation between individual stalls in a parlor. Because most cows are milked in a different stall at each milking, it has been proposed that stall deviations that represent the fixed effect of stall on milk weight could be statistically determined. Individual milk weights from 14 milkings across $7 \mathrm{~d}$ from approximately 200 cows were collected from the Penn State dairy farm, which is equipped with a double-10 herringbone parlor with an Afimilk 2000 milking system (S.A.E. Afikim, Afikim, Israel). Milk yield was measured automatically by in-line flow through milk meters (Afi 200; S.A.E. Afikim). The effect of stall on milk weight was modeled using a mixed model that included the fixed effect of stall and the random effects of day, milking time, and cow. First, stall deviations were calculated as the stall least squares means (LSM) minus the average LSM to identify malfunctioning meters requiring service (e.g., deviation exceeding $1 \mathrm{~kg}$ ). A correction factor for each
\end{abstract}

Received August 20, 2019.

Accepted January 6, 2020.

${ }^{*}$ Current address: Pasture Systems and Watershed Management Research Unit, USDA-Agricultural Research Service, University Park, PA 16802-3702.

†Current address: Dairy and Food Science Department, South Dakota State University, Brookings 57007.

$\ddagger$ Current address: Department of Medicine, Penn-CHOP Lung Biology Institute, Penn Cardiovascular Institute, University of Pennsylvania, Philadelphia, PA 19104.

§Corresponding author: kjh182@psu.edu stall was then generated by dividing the LSM of each stall by the average LSM. Milk yields were then corrected by multiplying the meter weight value by the correction factor. To determine the effect of the correction, raw and corrected meter values were compared with weight of milk collected in a bucket $(\mathrm{n}=3$ /stall). The corrected values had a $5 \%$ greater coefficient of determination than raw meter values (0.89 vs. 0.84) and had a lower average percent difference from the bucket milk weight compared with raw meter values $(12.6 \%$ vs. $13.5 \%)$. The method was then used in 3 experiments with 121, 140, and 683 milk yield observations. In all data sets, correcting milk weights slightly improved model fit and had minimal effect on model term standard errors. However, this validation was completed in a parlor where the method was routinely used to identify stalls requiring service; the effect of stall corrections is expected to be larger in parlors without frequent monitoring. Stall deviations are expected to be due predominantly to calibration of the meter but also could be due to differences in pulsation or other stallspecific factors that result in a change in milk yield. It is important to account for these other sources of milk weight variation that are unrelated to treatment. Modeling the effect of stall is a simple, convenient, and low-cost method to monitor and improve milk meter precision and functionality and can be used to reduce artificial variation and experimental error.

Key words: milk yield, milking parlor, flow meter, calibration

\section{Technical Note}

Milk yield is a fundamental observation in most dairy experiments and is commonly measured using commercial milk meters that determine milk weight during milking. These meters also serve important management functions on commercial dairies for cow and herd monitoring. Despite the importance of meter accuracy and precision, calibration of individual milk meters is commonly ignored. Milk meters require regular maintenance like most sensitive instruments, 
particularly because they are subject to heavy use in a harsh environment. For example, if a 500-cow dairy was milking 3 times daily in a 20 -stall milking parlor, each meter would be used 75 times per day. Heavy use coupled with the harsh environment typical of a milking parlor can lead to mechanical or electronic issues. This can cause the meter calibration to drift, resulting in increased variation and decreased precision of milk weights.

The most common method of calibrating a parlor is by comparing the total yield reported by milk meters with the total milk in the bulk tank plus unsaleable milk. Milk meter calibrations are then adjusted uniformly to align these 2 values. However, this ignores offsetting errors of over- and underestimating meters and provides no indication of which meters are malfunctioning. Regular calibration of meters may be overlooked because of time, cost, or other constraints. Direct calibration of meters by collection of milk in a bucket for multiple individual cow milkings is difficult and time consuming and can be inaccurate. Even if meters are checked and calibrated every 2 to 3 mo as commonly recommended, milk weight observation periods for research experiments are often only a few days or weeks long. A meter may become uncalibrated soon after the last check and remain uncalibrated through the duration of a research study.

The statistical effect of the stall or milk meter over many milkings could provide insight into the precision of individual milk meter measurements. Precision reflects the variability of measurements (e.g., how different the average milk yields for each stall are from one another), whereas accuracy reflects distance from the "true" value (e.g., how far each stall's average milk yield is from the "true" average). Manual weighing of milk would improve both precision and accuracy but is laborious and can be imperfect. Additionally, for many experiments, the main concern is determination of differences between treatments, and thus precision of milk yield measurements is of greater importance than accuracy. Determining the statistical effect of stall would enable producers and researchers to frequently check stall precision with greater ease and lower cost than manual weighing of milk. The first objective of this study was to define a method to check precision of milking parlor meters using a statistical model. The second objective was to determine whether adjusting milk weights using model-derived correction factors would improve precision of meters and decrease residual variance in experiments. We hypothesized that modeling the effect of stall on milk weight would enable detection of imprecise or uncalibrated stalls and that adjusting milk weights using model-derived correction factors would reduce experimental error for milk yield in research experiments.

The effect of stall on milk yield was modeled in $\mathrm{R}$ version 3.4.4 with the lme4 package (Bates et al., 2015; $\mathrm{R}$ Core Team, 2018) using $7 \mathrm{~d}$ of milk weight data from approximately 200 cows milked in a double-10 DeLaval Olympic Herringbone parlor (Tumba, Sweden) with an Afimilk 2000 milking system (S.A.E. Afikim, Afikim, Israel; Appendix Figure A1). Milk yield was measured automatically by in-line flow through milk meters (Afi 200; S.A.E. Afikim), with the herd averaging approximately $38.5 \mathrm{~kg} / \mathrm{d}$. A data window of $7 \mathrm{~d}$ was selected based on iterations with varied number of days and should be suitable for most herds but will depend on herd and parlor size. Milkings of less than $9 \mathrm{~kg}$ or more than $41 \mathrm{~kg}$ were excluded from the data set because they were likely incomplete milkings or milkings subsequent to incomplete milkings. Cutoffs for removal of data points were determined by assessing box and scatter plots of multiple milkings and from experience with Penn State University herd milk yields. The mixed model, referred to here as the stall calibration model, was

$$
\mathrm{Y}_{\mathrm{ij}}=\mu+\mathrm{S}_{\mathrm{i}}+\mathrm{C}+\mathrm{D}+\mathrm{T}_{\mathrm{j}}+\mathrm{T} \times \mathrm{D}+\mathrm{e}_{\mathrm{ij}},
$$

where $Y_{i j}$ is milk weight, $\mu$ is the overall mean, $S_{i}$ is the fixed effect of stall ( $\mathrm{i}=$ stall 1 to 20 ), $\mathrm{C}$ is the random effect of cow, D is the random effect of date of observation, $\mathrm{T}$ is the random effect of time $(\mathrm{j}=\mathrm{a} . \mathrm{m}$. or p.m. milking), $\mathrm{T} \times \mathrm{D}$ is the interaction of milking and date, and $\mathrm{e}_{\mathrm{ij}}$ is residual error. The interaction term is not expected to affect model outputs but should be run initially to check for potential effects of equipment or human error on $1 \mathrm{~d}$ of milking. If outputs with and without the interaction term are similar, the term can be dropped. All results presented here were generated from models not including the interaction term. Stall deviations were calculated as the stall least squares means (LSM) minus the overall average LSM ( $\boldsymbol{\mu L S M}$ ) to identify malfunctioning meters requiring service (e.g., stall deviation of $\pm 1 \mathrm{~kg}$ ), and then a correction factor for each stall was calculated as the stall's LSM divided by the $\mu$ LSM. Milk weights were then adjusted by multiplying the raw meter weight by the correction factor for the meter or stall.

To manually validate this method, milk was captured in an in-line bucket between the meter and the parlor milk line. Before the validation, stall deviations were determined to identify stalls that required service, and all stall deviations were within $2.3 \mathrm{~kg}$ from the $\mu \mathrm{LSM}$. Care was taken to maintain milk line angle to not disrupt the meter reading. The bucket was weighed 
before and after milking on a platform scale $(0.045-\mathrm{kg}$ increments; Smart Weigh, FBA ACE200; BetterBasics, Chestnut Ridge, NY). The meter and corresponding bucket milk weight were recorded 3 times for each stall $(\mathrm{n}=60)$. This enabled direct comparison of raw meter, corrected meter, and "true" milk weight in the bucket. To standardize across all weights, raw meter and corrected meter weights were converted to percent difference from their corresponding bucket milk weight (Figure 1). For example, if the bucket milk weight was $10 \mathrm{~kg}$ and the raw meter weight was $9.5 \mathrm{~kg}$, the raw meter weight was $-5 \%$ different from the bucket weight.

Applying correction factors reduced the difference between the meter and bucket milk weights. Raw meter weights were on average $13.5 \%$ different from bucket weights; applying correction factors to raw meter weights reduced this by 0.9 percentage units on average (e.g., $12.6 \%$ different from corresponding bucket weight). Correction factors did not uniformly decrease percent difference from the bucket, as the change for individual stalls ranged from an 11-percentage-unit decrease, becoming almost identical to the bucket weight, to a 5-percentage-unit increase, resulting in deviation further from the bucket weight. The coefficient of determination $\left(\mathrm{R}^{2}\right)$ of correlation between raw meter and bucket milk weights before correction was 0.84 and increased to 0.89 after correction (Appendix Figure A2). It is also important to note that the effect of the correction factors depends on the calibration of the parlor at the time of the test and whether stall deviations were routinely being checked to identify imprecise meters before this test. The correction factors would have a greater potential to reduce variation in a poorly monitored parlor.

The correction factor generated from the model correlated with the actual measured difference between the raw meter and bucket milk weights $\left(R^{2}=0.58\right.$; Figure 1). Because correction factors reflect the difference between the meter and bucket milk weights, the size of the correction factor can therefore be used as an indicator of a stall's calibration. A correction factor of 1 indicates perfect calibration, a factor below 1 indicates overestimation of milk weight, and a factor above 1 indicates underestimation of milk weight.

To assess the effect of adjusting milk weights on experimental model fit, the correction procedure was applied to milk weights from 3 prior research studies. The 3 experiments were well-controlled feeding experiments conducted at the Penn State University dairy, with 140, 683, and 121 milk weight observations in experiments 1,2 , and 3 , respectively. The stall calibration model was run for each experimental period within each study using milk weight data from the herd in the $7 \mathrm{~d}$ before the experimental observation period. Milk weights from cows enrolled in the experiment were omitted from the data set used to determine correction factors because they may be affected by treatments and may bias the model. Correction factors were applied to each milk meter observation in the experiment, and then milk weights were summed within day and averaged across 3 d. Akaike information criterion, Bayesian information criterion, model $\mathrm{R}^{2}$ (calculated by regressing estimated and actual milk weights), and changes in standard error of model terms were used to compare changes in model fit when using raw versus corrected milk weights.

In all experiments, both Akaike information criterion and Bayesian information criterion scores of experimental models were improved by using corrected milk weights compared with raw values. Using corrected values in the model improved $\mathrm{R}^{2}$ in experiment 2 and when data from all 3 experiments were combined but did not change $\mathrm{R}^{2}$ for experiments 1 and 3 (Table 1 ). Standard errors for all model terms decreased by about $1.5 \%$ in experiment 1 and increased by less than $1 \%$ for all terms in experiments 2 and 3. Applying the described corrections method to milk weight data slightly improved model fit and had minimal effect on variation in milk weight data. However, it should be noted that stall deviations were checked on a weekly basis during each experiment to identify drifting stalls, and stalls were flagged for repair if their LSM deviated by $20 \%$ or more from the $\mu \mathrm{LSM}$. In the 3 experiments, correction factors of individual stalls ranged from 0.87 to 1.26 (10th percentile $=0.95$, 90th percentile $=1.07$; Appendix Figure A3). Correction factors in these studies represent improvements in a well-maintained parlor, and a larger effect is expected in parlors that are not monitored or well maintained during data collection. Additionally, averaging milk yield across $3 \mathrm{~d}$ dilutes the influence of uncalibrated stalls but also reduces the influence of adjusting milk weights via the stall corrections model. A larger effect is expected in time course experiments with daily observations. A similar approach was used to calibrate meters in 2 different milking parlors at the University of Wisconsin with similar results (data not shown; Perfection 3000, Boumatic LLC, Madison, WI, and Metatron 21, GEA, Düsseldorf, Germany).

It is important to note that the stall correction factors calibrate milk yield relative to the average stall and increase the precision of the observations but do not compare with an absolute weight. As previously mentioned, precision of milk meters is of primary importance, particularly when comparing differences between treatment means. Most stalls with high stall deviations lack both precision and accuracy, and applying the stall corrections method increases precision by reducing variation in measurement ability between stalls. Increased accuracy can also be achieved by using 
the correction procedure described in conjunction with correcting for bulk tank or shipping weight plus unsaleable milk. After individual stall corrections are applied, the bulk tank weight plus unsaleable milk versus total milk harvested in the parlor can be compared to generate a bulk tank correction factor that can be applied across all stalls to increase accuracy. Another important consideration is that although the most common reason

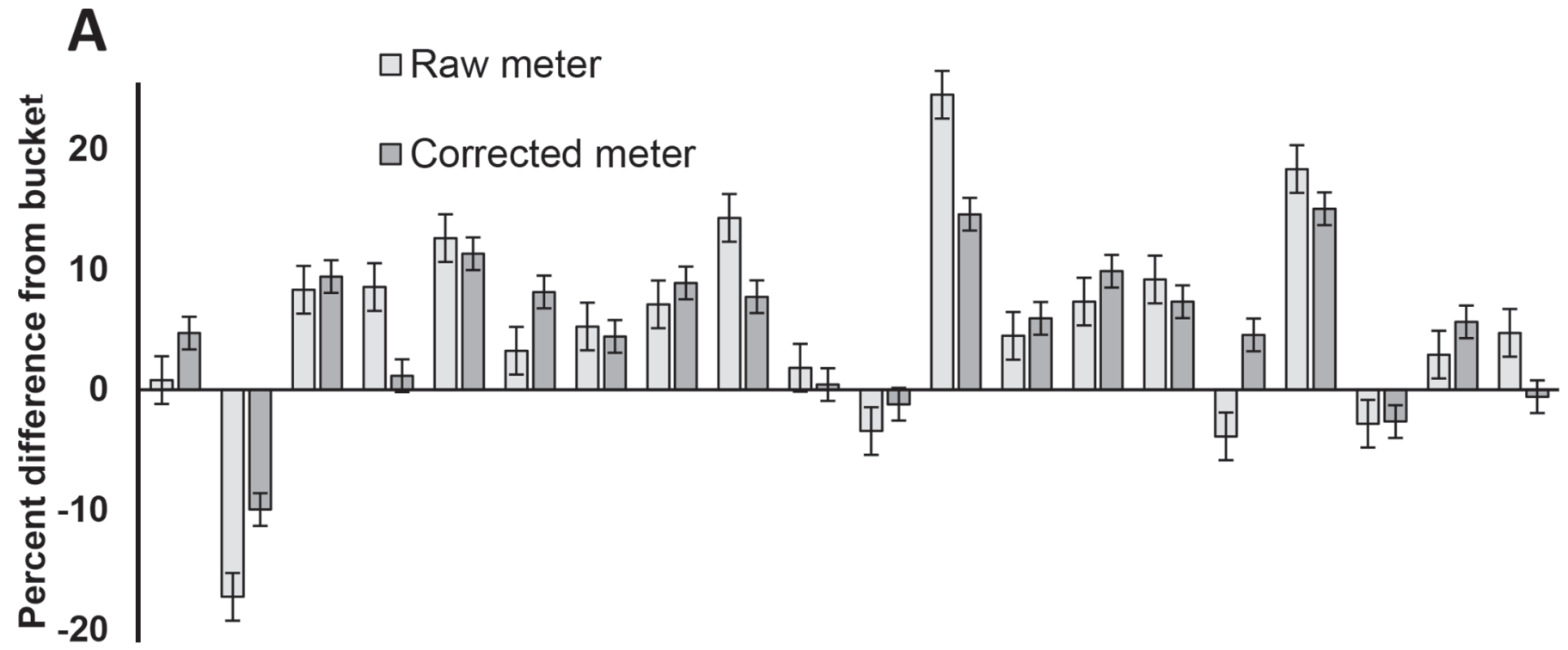

$\begin{array}{llllllllllllllllllll}1 & 2 & 3 & 4 & 5 & 6 & 7 & 8 & 9 & 10 & 11 & 12 & 13 & 14 & 15 & 16 & 17 & 18 & 19 & 20\end{array}$

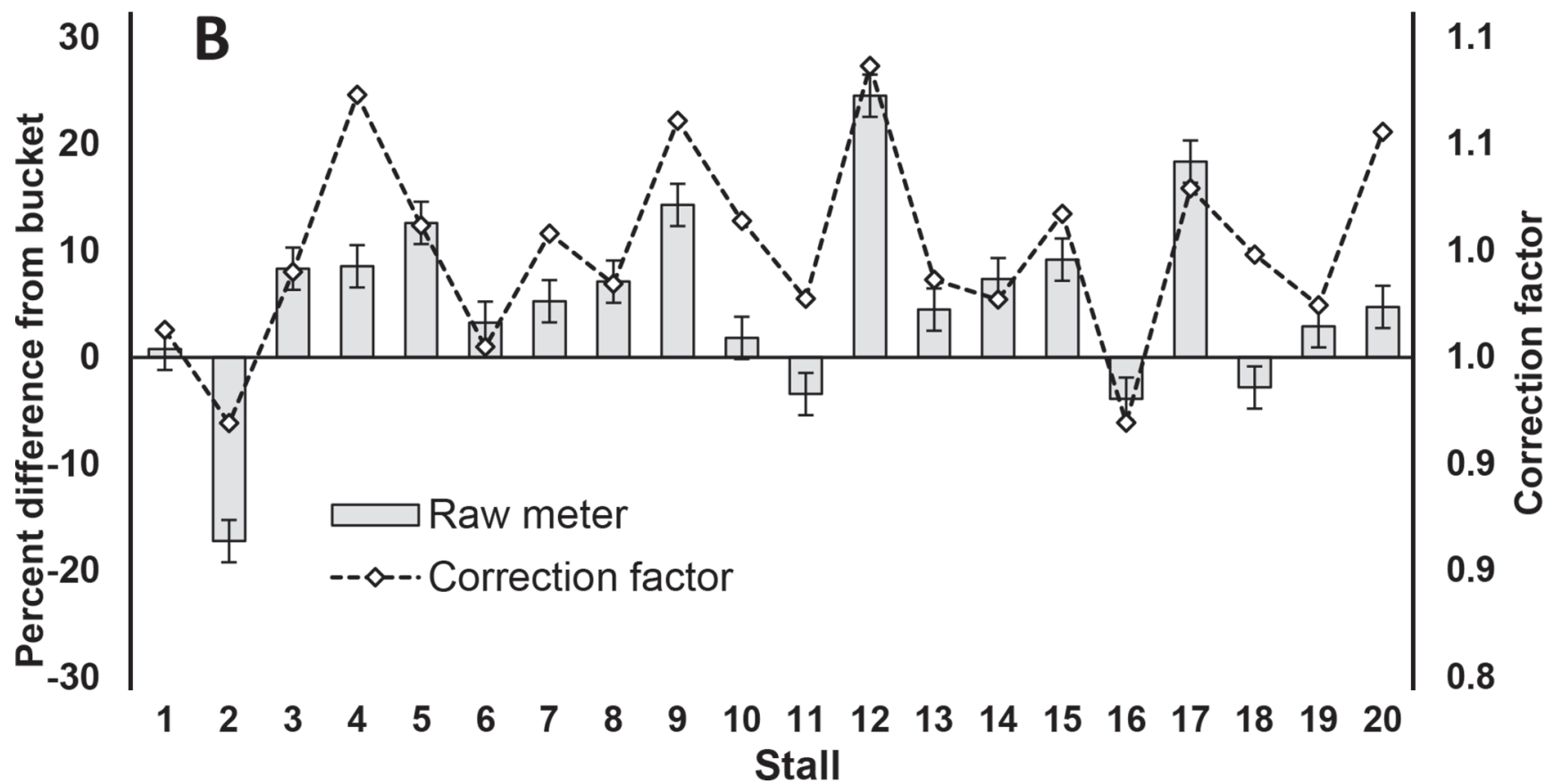

Figure 1. During 3 milkings in the Penn State University parlor (University Park, PA), milk was captured in an in-line bucket between the meter and the parlor vacuum line for manual weighing to compare raw meter weight and "true" weight in the bucket ( $\mathrm{n}=60$ ). Correction factors generated from the stall calibration model were applied to individual raw meter weights to obtain corrected weights. Raw meter and corrected weights were standardized to percent difference from their corresponding bucket weight and then were averaged by stall. (A) Average percent difference from bucket milk weight of raw meter weights versus corrected meter weights by parlor stall. (B) Relationship between raw meter percent difference from bucket milk weight and corresponding correction factor. Correction factors are expressed as (correction factor) ${ }^{-1}$. Error bars indicate standard errors. 
Table 1. Changes in SE and model fit statistics for 3 experiments when uncorrected versus corrected milk weight values were used in experimental models

\begin{tabular}{|c|c|c|}
\hline Experiment $^{1}$ and statistics & $\mathrm{Raw}^{2}$ & Corrected $^{3}$ \\
\hline \multicolumn{3}{|l|}{$\overline{\text { Experiment } 1(\mathrm{n}=140)^{4}}$} \\
\hline $\mathrm{BIC}$ & 821 & 797 \\
\hline AIC & 820 & 796 \\
\hline $\mathrm{R}^{2}$ & 0.99 & 0.99 \\
\hline \multicolumn{3}{|l|}{ SE } \\
\hline Treatment & 6.69 & 6.58 \\
\hline Phase $^{5}$ & 6.70 & 6.59 \\
\hline Treatment $\times$ phase & 6.77 & 6.67 \\
\hline \multicolumn{3}{|l|}{ Experiment $2(\mathrm{n}=683)$} \\
\hline BIC & 4,637 & 4,630 \\
\hline AIC & 4,492 & 4,486 \\
\hline $\mathrm{R}^{2}$ & 0.88 & 0.90 \\
\hline \multicolumn{3}{|l|}{ SE } \\
\hline Treatment & 3.89 & 3.93 \\
\hline Phase & 3.79 & 3.82 \\
\hline Treatment $\times$ phase & 3.99 & 4.01 \\
\hline \multicolumn{3}{|l|}{ Experiment $3(\mathrm{n}=121)$} \\
\hline $\mathrm{BIC}$ & 787 & 779 \\
\hline AIC & 784 & 775 \\
\hline $\mathrm{R}^{2}$ & 0.92 & 0.92 \\
\hline \multicolumn{3}{|l|}{ SE } \\
\hline Treatment & 5.00 & 5.05 \\
\hline \multicolumn{3}{|l|}{ Cumulative $(\mathrm{n}=944)$} \\
\hline $\mathrm{R}^{2}$ & 0.90 & 0.91 \\
\hline
\end{tabular}

${ }^{1}$ Experiments 1, 2, and 3 were well-controlled feeding experiments at the Penn State University (University Park) dairy. Experimental models (output variable $=$ milk yield) specific to each experiment were run with raw versus corrected milk weights to determine how using corrected weights affected model fit statistics. BIC $=$ Bayesian information criterion; AIC $=$ Akaike's information criterion.

${ }^{2}$ Raw meter values obtained from the stall milk meter.

${ }^{3}$ Milk meter values after correction factors obtained from the stall calibration model were applied. Correction factors were applied to each milk meter observation in the experiment, and then milk weights were summed within day and averaged across $3 \mathrm{~d}$. The stall calibration model was run for each experimental period within each study using milk weight data from the herd in the $7 \mathrm{~d}$ before the experimental observation period.

${ }^{4} \mathrm{n}=$ number of milk weight observations entering the experimental model. Each observation was the average of $3 \mathrm{~d}$ of milk weights.

${ }^{5}$ Experimental treatment phase. Experiments 1 and 2 were divided into periods, with 3 dietary phases within each period.

for large stall deviations is uncalibrated milk meters, issues with the pulsator, vacuum, or other variables can influence milk production in a stall. When stalls are flagged by the calibration model, it is important to determine the root cause of the deviation to correct the issue. Last, it should be noted that the procedure described here was developed and validated using specific milking equipment and software. The principle of the approach should be conserved across systems, but care should be taken in its application to other systems.

The stall calibration model assumes that cows are milked in different stalls to allow parameterization of cow and stall. It is common to observe some cows enter the same stall repeatedly, typically one of the first 3 stalls of the parlor. We observed individual cows enter- ing the same stall in up to 10 out of 14 milkings in one 7-d observation period. However, the number of cows that entered the same stall more than $50 \%$ of the time was 3 to 7 cows out of approximately 200, but this may vary between farms and groups. Importantly, cow was a random effect in the stall calibration model, and the small number of cows repeatedly entering one stall is not expected to greatly influence correction factors.

In conclusion, milk meter precision is a key point of variation in dairy experiments, and the proposed method to determine stall deviations is fast, easy, and economical compared with manually weighing milk or professional calibration. The procedure can be performed in any statistical program with mixed modeling capabilities, including $\mathrm{R}$, which producers or consultants can download for free (R Core Team, 2018). Stall deviations are a useful approach to identifying milk meters requiring service, and the stall calibration model offers the option of mathematically adjusting milk weights for deviation between stalls, which has been demonstrated to provide a slight benefit to experimental model fit. The method presented also is valuable to commercial farmers because it improves validity of management decisions based on milk yield changes, such as genetic selection or nutrition changes.

\section{ACKNOWLEDGMENTS}

Funding was provided in part by Agriculture and Food Research Initiative Competitive Grant No. 201567015-23358 from the USDA National Institute of Food and Agriculture (Washington, DC) and Penn State University (University Park, PA), including USDA National Institute of Food and Agriculture Federal Appropriations under project number PEN04539 and accession number 1000803. We thank R. Shepardson, B. Bomberger, and C. Matamoros, all of Penn State University, for assistance with data collection. The authors recognize key discussions and contributions from L. Armentano (University of Wisconsin, Madison). The authors have not stated any conflicts of interest.

\section{REFERENCES}

Bates, D., M. Mächler, B. Bolker, and S. Walker. 2015. Fitting linear mixed-effects models using lme4. J. Stat. Softw. 67:1-48. https:// doi.org/10.18637/jss.v067.i01.

R Core Team. 2018. R: A Language and Environment for Statistical Computing. R Foundation for Statistical Computing, Vienna, Austria.

\section{ORCIDS}

D. M. Andreen ( https://orcid.org/0000-0002-2848-126X I. J. Salfer ๑ https://orcid.org/0000-0001-5895-8172

K. J. Harvatine (ํ) https://orcid.org/0000-0001-6422-2647 


\section{APPENDIX}

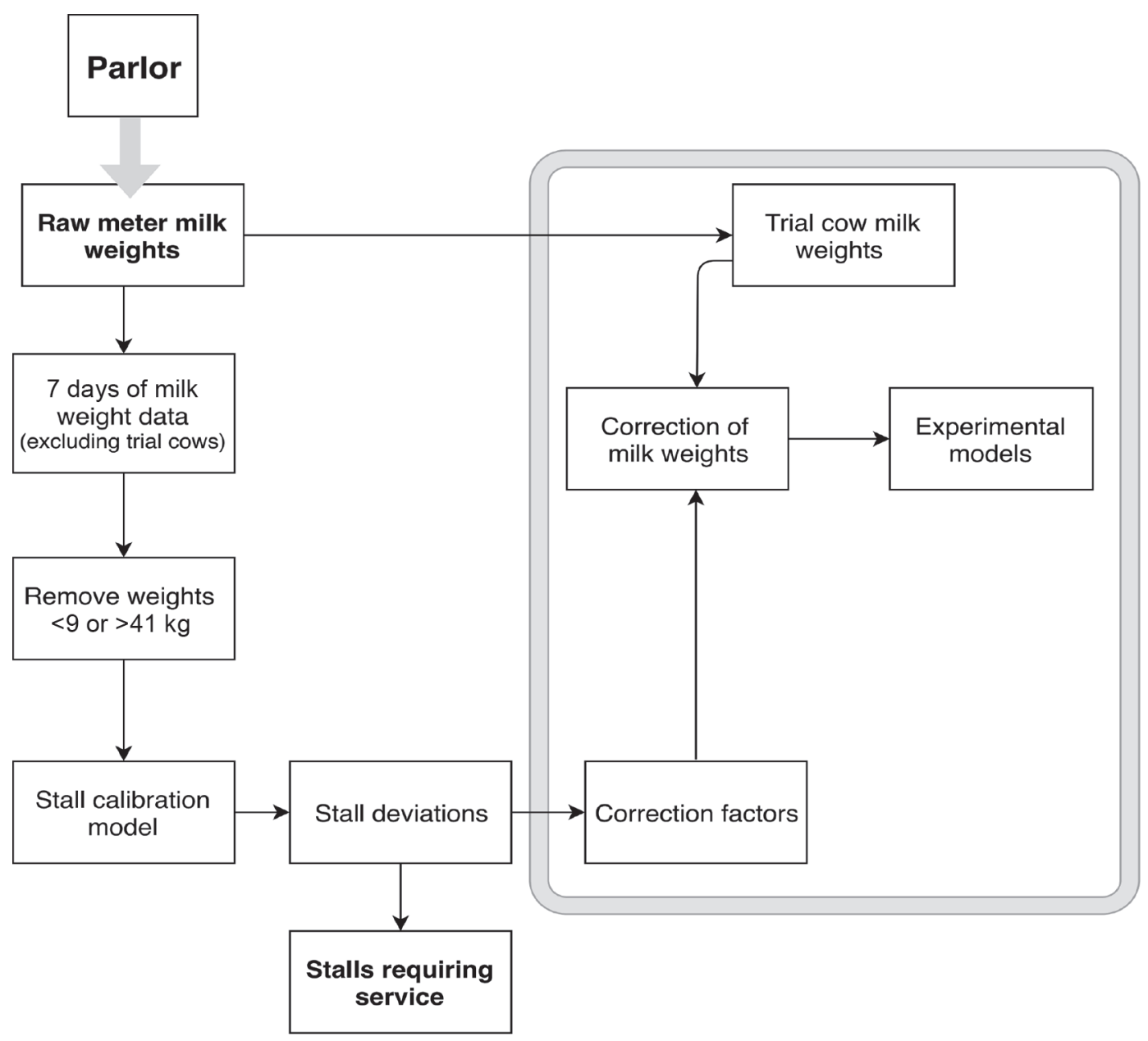

Figure A1. Flowchart of experimental methods to obtain stall deviations and stall correction factors. Steps in the gray rectangle are optional (e.g., for research purposes) to correct milk weights for stall effects. Seven days of milk weight data from the entire herd should be collected, and weights of $<9$ or $>41 \mathrm{~kg}$ should be removed. These data can enter the stall calibration model, which will produce stall deviations that indicate which stalls, if any, require service or other intervention. If desired, stall deviations can be converted to correction factors and applied to cow milk weights by stall. 

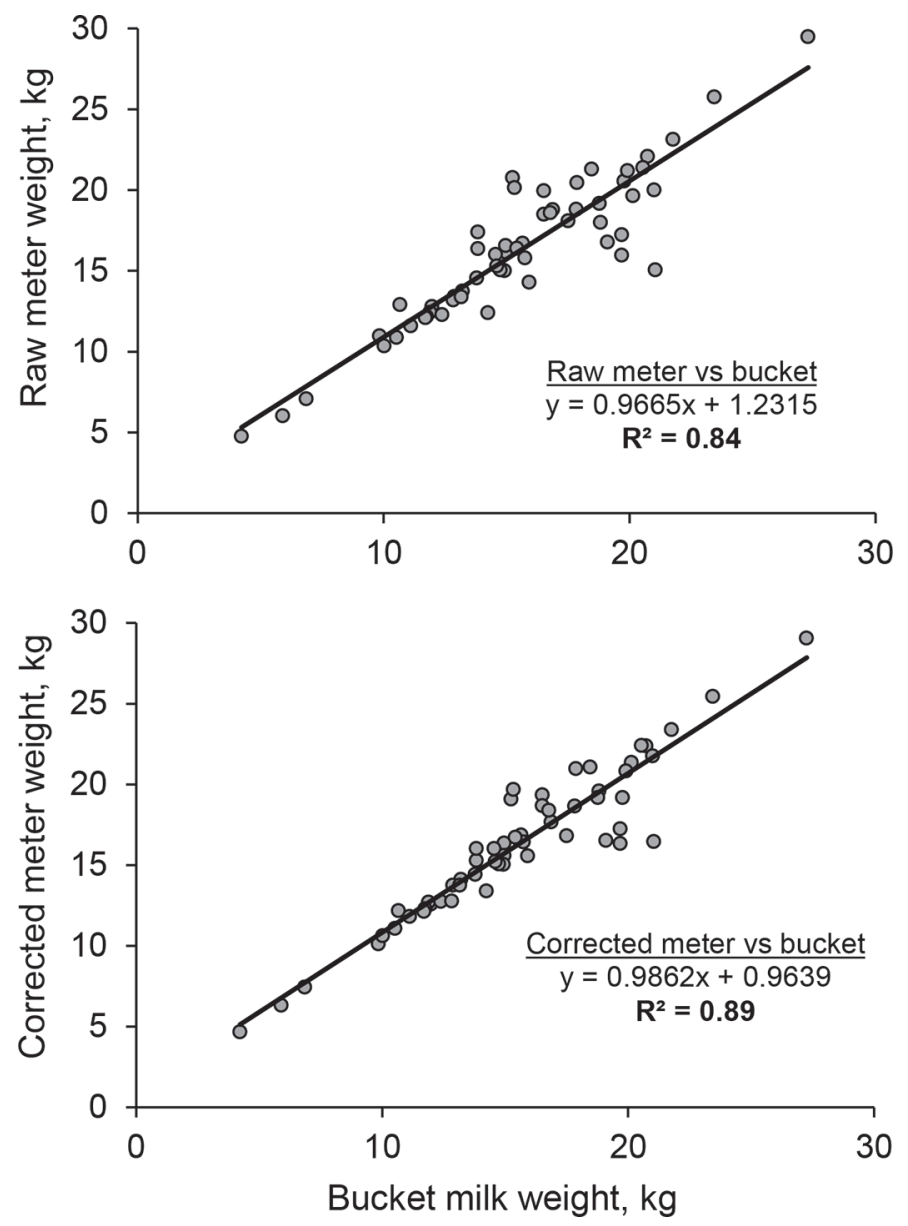

Figure A2. Regressions of raw meter weight versus bucket weight (top) and corrected weight versus bucket weight (bottom). During 3 milkings in the Penn State University parlor (University Park, PA), milk was captured in an in-line bucket between the meter and the parlor vacuum line for manual weighing $(\mathrm{n}=60)$. Correction factors generated from the stall calibration model were applied to individual raw meter weights to obtain corrected weights. Raw meter weights and corrected weights were regressed with corresponding bucket weight to determine difference in coefficient of determination. 


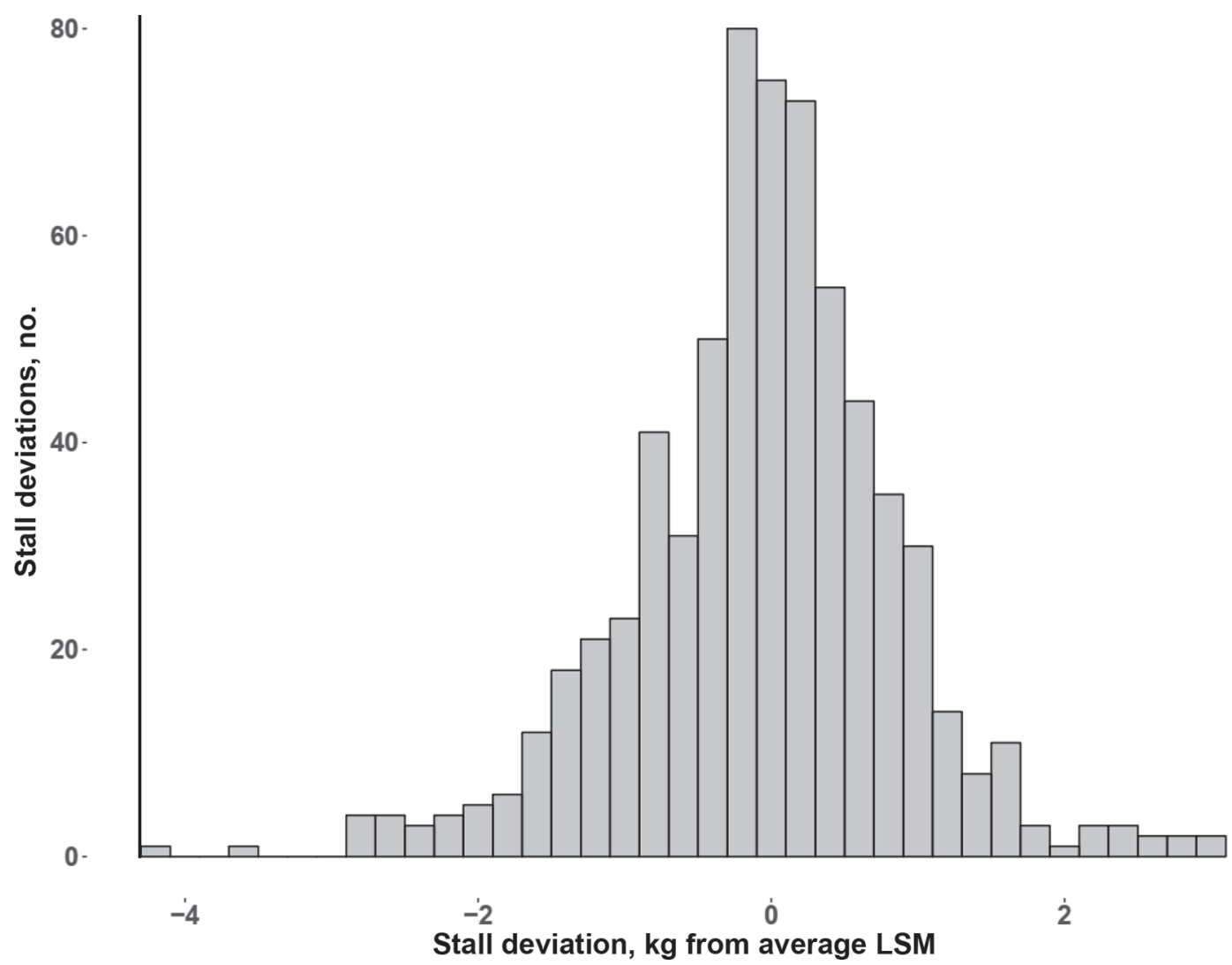

Figure A3. Histogram of individual stall deviations (kg) above or below corresponding mean LSM. Deviations shown are from 3 nutrition experiments at the Penn State University dairy (University Park, PA) where the stall calibration model was run either weekly throughout the experiment (experiments 1 and 3) or once before the experimental period (experiment 2). 